\title{
Intention and Attempt
}

\author{
Vincent Chiao
}

Version Publisher's Version

Citation Vincent Chiao, "Intention and Attempt" (2010) 4 Criminal Law \& (published version) Philosophy 37.

Publisher's Statement This article has been reproduced with the permission of Springer International. The final publication is available on https://doi.org/10.1007/s11572-009-9085-6

How to cite TSpace items

Always cite the published version, so the author(s) will receive recognition through services that track citation counts, e.g. Scopus. If you need to cite the page number of the author manuscript from TSpace because you cannot access the published version, then cite the TSpace version in addition to the published version using the permanent URI (handle) found on the record page.

This article was made openly accessible by $U$ of $T$ Faculty. Please tell us how this access benefits you. Your story matters. 


\title{
Intention and Attempt
}

\section{Vincent Chiao}

(C) Springer Science+Business Media B.V. 2009

\begin{abstract}
Anglo-American criminal law traditionally demands a criminal purpose for an attempt conviction, even when the crime attempted requires only foresight or recklessness. Some legal philosophers have defended this rule by appeal to an alleged difference in the "moral character" or "intentional structure" of intended versus non-intended harms. I argue that there are reasons to be skeptical of any such differences; and that even if conceded, it is only on the basis of an unworkable view of criminal responsibility that such a distinction would support a rule restricting attempts to criminal purpose. I defend instead the "continuity thesis," according to which attempts are functionally continuous with endangerment offenses: both are legal efforts to regulate unreasonably dangerous conduct. The upshot of the continuity thesis is that there is little substantive difference between attempt and endangerment in principle, no matter how they are labeled in law.
\end{abstract}

Keywords Attempt $\cdot$ Mens rea . Intention $\cdot$ Foresight

In addition to protecting vital interests from third-party invasion, Anglo-American criminal law also penalizes conduct that merely jeopardizes those interests. For instance, in the law of attempts, an agent who tries unsuccessfully to invade a protected interest is nevertheless punishable, though perhaps not to the same extent had she succeeded. Statutes that penalize "reckless endangerment" provide a similar form of protection against dangerous, but not ultimately harmful, conduct. However, despite this similarity, some legal philosophers have argued that attempt and endangerment statutes perform importantly different functions. Philosophers who take this view are inclined to claim that there is something unique about the "moral character" or "intentional structure" of intended harming that justifies singling it out as of special salience under the heading of "attempt" rather than (mere) "endangerment." These philosophers are thus able to provide a principled foundation for the broadly accepted and traditional rule in Anglo-American criminal law that liability for a criminal attempt requires the agent to have acted with the purpose of bringing about the

V. Chiao $(\bowtie)$

Harvard Law School, 23 Everett St., Room 326, Cambridge, MA 02138, USA

e-mail:vchiao@law.harvard.edu 
criminal result, even in cases where the underlying offense does not (what I shall call the traditional mens rea rule of attempts). On this view, intended attempts to harm are morally distinct from reckless or knowing endangerments, and this moral distinction is and ought to be given legal effect in criminal codes. ${ }^{1}$

I am dubious that the distinction between attempt and endangerment is nearly as firm as these philosophers suggest. This is because the best principled arguments in favor of distinguishing them rest on appeals to the uniqueness of intended harming, but (a) the arguments put forward to establish this alleged uniqueness are uncertain; and, more importantly, (b) the moral status of intended wrongdoing only matters on the tacit presupposition of a fundamentally flawed view of criminal responsibility. Appreciating these two points lends support to the proposition that attempt and endangerment offenses are broadly continuous, in that they are two ways the criminal law has of achieving one ultimate end, namely the regulation of unreasonably dangerous conduct. A consequence of viewing attempt and endangerment in this light is that the current doctrinal structure of many jurisdictions appears to suffer from an indefensible gap: when it fails to cause harm, conduct that recklessly or knowingly threatens to invade a legally protected interest is either not punishable at all, or punishable only relatively mildly, even though it may be punished quite harshly if it unluckily does cause harm. This gap should be filled either through relaxing the purpose requirement for attempts, or by adopting a more complex endangerment statute that creates endangerment offenses of varying degrees, with penalties for the most aggravated falling somewhere between the penalty for misdemeanor endangerment on the one hand, and the penalty for the actual (successful) offense on the other.

\section{Some Initial Issues}

Before starting, I should define the class of attempts in which I am interested, and clarify just what is and is not at stake in the argument.

My concern here is (roughly) with what are traditionally known as "complete" attempts. Complete attempts are attempts where the agent has taken the last step in her plan

\footnotetext{
1 The rule is broadly, but not invariably, accepted. See United States v. Gracidas-Ulibarry, 192 F.3d 926, 932 (J. Silverman, dissenting) (1999) ("It is an axiom of American criminal law that an attempt 'includes an element of specific intent even if the crime attempted does not." ) The Model Penal Code adapts a modified version of the rule, considering knowledge of a criminal result as sufficient (see MPC \$5.01(b)). According to Antony Duff, England conforms to the traditional rule, whereas Scots law takes a more expansive view of attempt (Duff 1990). For detailed discussion of the forms of attempt and reckless endangerment in the United States (see Cahill 2007, pp. 913ff.). Cahill's research indicates that a plurality of the 37 states in the United States that have defined attempt provisions adopt the traditional requirement of criminal purpose as to the results. Twenty states are strict on this point, and an additional ten follow the Model Penal Code in allowing foresight to count, at least with reference to completed attempts. Apparently only three statesColorado (Colo. Rev. Stat. Ann. §18-2-101(1) (1986)), Indiana (Ind. Code Ann. §35-41-5-1(a)) and North Dakota (N.D. Cent. Code §12.1-06-01 (1997))_directly identify the culpability of an attempt with that of the underlying offense. (Cahill includes Utah in this latter group, but Utah Code Ann. §76-4-101(1)(b) clearly indicates that Utah follows the Model Penal Code with respect to completed attempts. Indeed, Utah is in fact stricter than the Model Penal Code, since State v. Casey, 82 P.3d 1106 (Utah 2003), established that Utah does not countenance attempt liability for anything short of a criminal intent, including knowledge.)

Academic commentary on the mens rea required for attempts is relatively sparse. For older discussions, see Smith (1957, 1962a, b), Stuart (1968), Wechsler et al. (1961a, b), Hart (2008) and Enker (1977). For more recent discussion, see Alexander and Kessler (1997), Duff (1989, 1990, 1995, 1996a, b, 2005) and Cahill (2007).
} 
of action, but has nevertheless failed to cause harm; incomplete attempts are those where the agent is stopped, or renounces, while there are still steps untaken. ${ }^{2}$

Although it is not crucial for my purposes here, I take a rather dim view of this distinction. The underlying distinction seems to be between a person who has tried to commit what amounts to a substantive offense but fails, and a person who has not yet gotten to the point of failing. But if so, it would be better to distinguish attempts in which there is no turning back (the trigger pulled; the bomb exploded; the pocket picked), from attempts in which there remains a possibility of renunciation that the agent knows she can take. Thus understood, the important contrast is not between a bomber with a week-long fuse and the bomber who takes a week to get to her destination; it is between both of those bombers and the one whose bomb has already detonated but failed to kill. ${ }^{3}$

The broader point is that complete and incomplete attempts, however distinguished, should be treated separately, as they raise distinct issues. Notably, there is a question regarding the degree of certainty with which we can predict what an incomplete attempter will do, an issue that simply does not arise from the ex post perspective of complete attempts. Moreover, the preparatory steps which can give rise to attempt liability may themselves be perfectly legal and, taken on their own, innocuous. It is thus likely that in some cases of incomplete attempts, it will be difficult to assess not just whether the agent will carry through with her criminal plan, but whether she has a criminal plan at all. For these reasons, it might be plausible to construe the criminal intent requirement as serving to filter out innocent agents with respect to incomplete attempts. But these concerns would of course be immaterial in the case of complete attempts, as I have distinguished them. So the traditional mens rea rule of attempts may well be intelligible with respect to one class of attempts but not the other.

Secondly, it is important to note that the debate about the mens rea of attempts is independent of the broader question of whether we should prefer subjectivist or objectivist theories of criminal responsibility. ${ }^{4}$ Although, as Antony Duff has noted, subjectivists have reason to endorse the view that attempts ought to be mens rea equivalent to the underlying offense, the converse is not true. ${ }^{5}$ One does not need to be a subjectivist to endorse the position defended here; the arguments I mount are independent of any characteristically subjectivist commitments. In particular, one can believe that reckless attempts should be punishable without believing that they are morally equivalent to, or should be punished as harshly as, recklessly caused harms. ${ }^{6}$ The argument of this paper is neutral on the broader debate concerning subjectivist and objectivist views of criminal responsibility.

Finally, one common defense of the mens rea rule of attempts can be dispensed with quickly. This is the suggestion that an attempt is a trying-to-do-X; and you cannot try to do $\mathrm{X}$ unless what you are intending by your actions is X. In other words, unless your intent in acting was to do $\mathrm{X}$, you cannot be said to have attempted to do $\mathrm{X}$; therefore, criminal

\footnotetext{
$\overline{2}$ See e.g., Wechsler et al. (1961a, p. 571).

3 For similar remarks, see Robinson (1997, pp. 157ff.), and Enker (1977, p. 850). See also Husak (2007, p. 160). My thanks to Ken Simons for discussion of these issues.

4 See Enker (1977), though what he has in mind by "subjectivism" has more to do with a comparative emphasis on culpability as against conduct (mens rea versus actus reus), rather than the problem of outcome luck.

5 See Duff (1996a, pp. 171ff.). Finkelstein (1999) describes this as "the subjectivist approach to attempt liability," (p. 76) and Husak (1997) implies that because the result is so (allegedly) counter-intuitive, Duff's argument essentially functions as a reductio (p. 301). Duff himself, it should be noted, does not make this claim.

${ }^{6}$ For general discussion of this issue, see Ashworth (1988) and Bittner (2008).
} 
attempts must be defined in terms of purpose. ${ }^{7}$ Suppose it is true that "attempting to X," as commonly understood, implies purposive striving toward X. What follows? Very little; for the substantive question is whether the law should or should not assign a penalty to a person who knowingly or recklessly imposes serious risks on others but, by sheer luck, does not harm them. Observations as to whether such behavior is properly called an "attempt" are not helpful in answering that question. ${ }^{8}$ I do not insist that we must call nonpurposive criminal risk-creation an "attempt." We can call it whatever we like, but we should not thereby be misled into thinking that the legal distinction between attempt and non-attempt cuts at any important moral joints. The important issue is whether there is anything specific to intended harming that justifies distinguishing it as having special moral and legal significance. If so, then the legal regulation of non-purposive endangerments would be distinct in principle from the regulation of purposeful attempts, no matter what we decide to call them. ${ }^{9}$

\section{Intended Harms, Attacks, and Practical Reasoning}

The most sophisticated defense of the traditional mens rea rule of attempts is provided by Antony Duff. Duff's strategy is to describe a difference in the "moral character" or "intentional structure" between intended and non-intended harmings, and to use that distinction to justify the claim that a person commits a graver wrong if she, rather than anticipating or exhibiting recklessness toward harm, actively intends it. From this, Duff concludes that we have "stronger reason" to criminalize (purposive) attempts than (nonpurposive) endangerments.

In this section, I raise some doubts about the first step in Duff's argument. I focus on two features of Duff's argument: that describing attempts as "attacks" adequately captures their allegedly distinctive moral character; and that an agent who intends harm acts out of worse reasons than one who merely foresees harm. In the next section, I question whether any such claim, even if granted, would support the mens rea rule of attempts.

(a) Duff suggests that intended harms are uniquely wrongful because of their status as "attacks." "An intended attack on another person," Duff writes,

retains its character as an attack even if it fails: but the expectation that I will harm another person as a side-effect of my action, while it displays a disregard for his interests which would make me fully responsible for that harm if it actually ensues, does not in the same way define my action itself, in the absence of such harm, as a wrongful attack. ${ }^{10}$

\footnotetext{
${ }^{7}$ Keys v. State, 766 P.2d 270, 273 (1988). ("Attempt means to try; it means an effort to bring about a desired result.")

${ }^{8}$ As Joshua Dressler crisply puts it, "if the only obstacle to permitting guilt for unintentional 'attempts' is the meaning of the word 'attempt,' legislators can simply change the name of the crime" Dressler (2007, p. 419). See also Duff (1990, pp. 195-196).

${ }^{9}$ The retort that legislators have in fact criminalized non-intentional attempts by defining crimes of reckless endangerment is thus off target. The sheer existence of endangerment offenses is not at issue; what is at issue is the relation between endangerment and attempt. Is endangerment simply an awkward way of filling the gap created by defining attempts as purposive, or is there an important philosophical reason for strictly distinguishing the two?

${ }^{10}$ Duff (1990, pp. 204-205); see also Duff (1996a, pp. 362ff.).
} 
As Duff points out, if A intentionally seeks to kill B, yet B survives, A will consider her action a failure, and will take herself to have reason to try again, whereas if A foresees B's death as a practically certain result of her conduct yet B survives, A will not necessarily consider her act to have failed, and may even be relieved. ${ }^{11}$ It is in this sense that Duff claims an intended goal provides the "focus" or "structure" or "essence" of an agent's actions in a way that a merely foreseen side-effect does not.

How much weight will this characterization of intended harms as attacks bear? Consider that the notion of an attack has its home in personal injuries: in crimes of rape, homicide and battery, where one individual inflicts bodily harm on another. But one can attempt to steal, to deceive, to commit fraud, to distribute drugs, to possess drugs, and so on; and the harmed party can be a reputation, the state, or everyone but no one in particular. ${ }^{12}$ It would seem implausible to suggest that the rationale for restricting attempts to purposive criminal conduct in these cases has much to do with the nature of intended harms as attacks, since the underlying offenses are not themselves attacks. While, as Duff rightly points out, we occasionally do describe conduct directed against practices, institutions and so forth as "attacks," the kind of intent that makes that description apt is notably not the kind of intent at issue when someone is prosecuted for a criminal attempt. After all, a person who purposefully refuses to pay her taxes may thereby intend to "attack" the institution of taxation, but she also might intend nothing of the sort. She may just have other reasons for doing what she-intentionally — does, for instance, a need to spend the money elsewhere. But the mens rea rule of attempts does not require that the agent express hostility toward the object of her attack; it only requires that she sought a certain aim intentionally, and that the aim be, in fact, criminal. (If A steals B's car in order to go on a joyride, A attacks B's interests; but if A steals B's car because she is convinced B is about to do something uniquely stupid with it, it seems strained to say A is "attacking" B-even though we might still describe what A did as "stole B's car.")

Now, one could regiment a technical sense of "attack," according to which A attacks B iff she intentionally causes what is in fact a legally recognized harm, regardless of her reasons or motivations for doing so. ${ }^{13}$ A person who intentionally fails to pay her taxes "attacks" the state in this sense, whatever her motives, just as a user of illicit drugs attacks the state when he buys or sells drugs, even if in doing so he acts akratically.

However, while a regimented sense of "attack" will indeed reach these cases, it will no longer explain why characterizing these cases as "attacks" has any consequences for their relative moral character. Consider one of Duff's examples: if A forces B into a game of Russian roulette, A attacks B just as much as if she punches him in the gut. But why is this, given that A does not intend to kill $\mathrm{B}$, though she foresees a substantial likelihood of his death? Duff writes, "we need only note that intended endangerments share the crucial feature of attacks: they are aimed against those whom the agent intends to endanger; they are intended to threaten, if not to harm, their victims' interests; they manifest hostility rather than mere indifference." ${ }^{14}$ But that an agent intends her conduct as a threat, or acts out of hostility rather than mere indifference seem to be clear cases of an agent's reasons or

\footnotetext{
11 See also Enker (1977).

12 For Duff's discussion of attempted drug crimes (see Duff 1996a, pp. 374-378).

13 Duff's preferred test for the intent requisite to constitute a legal attack is "an intention such that the agent would necessarily commit a complete offence in carrying it out."

${ }^{14}$ Duff (2005, p. 51).
} 
motives for doing what she does. ${ }^{15}$ And this is no accident, since what is illuminating about describing conduct as an attack is that doing so reveals something about the agent's underlying attitudes, namely, that they are revealed as particularly vicious. The intuitive sense of attack relies on the concept's connection to claims about an agent's attitudes, and thus may explain why attacks are uniquely wrongful. But for that very reason, it is of limited usefulness when we consider the broad scope of attempt liability. Conversely, any sense of attack that severs those connections will purchase generality at the cost of making it unclear why the law should care specially about "attacks," thus defined, in the first place. So while the regimented sense of attack will indeed reach akratic A, who regretfully attempts to sell drugs to support her own habit, it will not do so in a way that suggests why it is desirable to reach her but not belligerent $\mathrm{B}$, who, on account of his antipathy toward state and community, is pointedly indifferent as to whether what he sells is a regulated substance.

It is more plausible to construe attempts as regulating attacks when we are focused on homicide, rape and battery since, in those cases, intent to cause the legally prohibited result is describable as intent to attack without further qualification. But that is not the case when we think of the broad reaches of criminal liability. Attempt is a general category ranging over many different substantive offenses, some of which have been created to deter attacks, some to regulate commerce, some to maintain social tranquility and other motives besides. But if substantive offenses need not be motivated by a concern to stop attacks, it is far from clear why attempts at those offenses should be. But if not, then even if intending a harm is "essentially" or "intrinsically" harmful, that may simply be beside the point for attempts at crimes which, when successful, would not naturally be understood as attacks of any kind.

(b) Duff has recently suggested another explanation for how the distinction between intended and non-intended wrongs should be understood. "The difference in moral character," Duff claims, “...lies in part in the difference between being guided by the wrong reasons and not being guided by the right reasons" (Duff 2005, p. 47). As I interpret it, Duff's suggestion is that when A attacks B, she acts on a reason that, far from morally validating what she does, exhibits the wrongness of her act, whereas, when A merely endangers B, she has failed at most to accurately weigh the risk to B against her (possibly legitimate) reasons for acting. ${ }^{16}$ This is what it means to be guided by "wrong reasons," rather than merely "not being guided by the right reasons." The latter is all that is true of the person who merely foresees harm, since that person is merely mistaken as to what the reasons support doing on net.

I have two worries about this argument. First, one may doubt that whenever an agent contemplates acting in a way that risks harming someone, the correct form of deliberation is simply weighing pros and cons. Although weighing may be involved, the sorts of considerations that may take on weight are restricted, and restricted in light of the nature of the risk imposed. This is clear if we think of the complaints of those who are exposed to the risk. Of course, one does not have standing to complain, morally or legally, each time

\footnotetext{
15 Similarly, Duff argues that A does not attack B if A acts out of self-defense. But acting out of selfdefense would seem to be one way of specifying a person's reasons or motivations for (intentionally) doing what she does (see Duff 1996a, p. 364, fn. 75).

16 Duff claims that a risk of harm "often provides a conclusive reason against the action" Duff (2005, p. 53). I understand Duff to mean that sometimes the foreseen harm is so great that it outweighs all other likely considerations, but not that it serves to rule out other sorts of considerations from legitimately entering into deliberation in the first place. Since I think foresight of harm can sometimes take the latter role, I think that acting in such circumstances is also to act for "wrong reasons," not merely to act on the basis of a misestimation of what one has all-things-considered reason to do.
} 
someone else's behavior puts one at risk; but sometimes one does. On some occasions, this is because the agent acted negligently, and failed to take cost-effective safety precautions - that is, did not accurately weigh costs against benefits. But sometimes one has reason to complain because the benefits the agent was trying to achieve simply do not count as against the risks imposed, not because the expected benefit was outweighed by the social costs.

To illustrate: A shoots at a house in which he believes rival gang-members are celebrating, hoping to hit his rivals but aware that he might hit the bystanders as well. ${ }^{17} \mathrm{On}$ Duff's account, A would be acting for a bad reason vis-à-vis the gang members (intending them harm), but would only be failing to act for right reasons vis-à-vis the bystanders (deeming the benefit to himself greater than the risk to them). This view suggests that A's conduct constitutes attempted murder as against the gang members, but only endangerment as against the bystanders, although A shot blindly through windows and doors, and thus was in no position to differentiate victims - a result which might make us uneasy. Regardless, suppose we are now asked whether A should be condemned for endangering the bystanders; it seems quite incredible to think that this question could only be answered by allowing $\mathrm{A}$ to take the stand to explain just how much his street credibility was enhanced. (Doctrinally speaking of course, A has no defense of justification based on the level of status-enhancement anticipated.) Although it may serve to make the action intelligible, that kind of reason carries no justificatory weight whatsoever, in light of the risks imposed.

This is not to say that no reasons for action could be considered, nor even that if reasons of that kind were present, that they would not then have to be weighed against the risk to the bystanders. But the risks A imposes serve as defeasible peremptory reasons: reasons which block assigning any weight to some, though not necessarily all, types of reasons for acting in that way. ${ }^{18}$ In acting on what is peremptorily ruled out as having any positive weight, however, A acts for a bad reason whether his conduct is intended to harm, or merely recklessly or anticipatorily risks harm. Status-enhancement does not count toward validating A's attempt to murder the rival gang members, but it also does not count toward validating A's endangerment of the non-gang members either. So if A acts on a bad reason in the former case, he also acts on a bad reason in the latter. In assessing A's conduct, the criticism we should make is not that A erred in assessing benefits and burdens, and thus took as rational what was in fact irrational. Rather, it should be that A was patently unreasonable in treating the enhancement of his social status as having any weight at all as against the risks he imposed; it is not the kind of action that would be justified by any plausible moral principle. A's unreasonableness is what gives the bystanders he risks

\footnotetext{
17 Based on the facts of Jones v. State, 689 N.E.2d 722 (1997), discussed in more detail below.

18 All that is meant by calling them defeasible is that the risks are not such that it would never be permissible for A to do what he does, only that it is never made permissible on the basis of certain kinds of reason. Might there be a difference between being motivated by what is not, in this context, a valid consideration at all, and being motivated by what is not, ever, a valid consideration? There might be, but since the argument I am considering founds the distinction between A (who intends harm) and B (who foresees it) on the structure of their practical reasoning, rather than the nature of the concrete reasons in each particular case, I don't think this claim, even if true, would help. Note that I am not claiming that intended and foreseen harms cannot be distinguished, but am defending only the much weaker claim that they are not distinguished on grounds that one agent violates a peremptory reason while the other merely miscalculates costs and benefits. In any case, it seems somewhat implausible to construe every case of an intended harm/ attack as a case of an agent acting for a categorically prohibited reason, especially if we keep in mind the broad scope of attempt liability. Duff, for one, certainly does not endorse such a claim; see Duff (1996a, p. 372).
} 
killing cause for complaint, and cause independent of exactly how much benefit A derives from shooting at them. ${ }^{19}$

But suppose it is true that those who intend to harm act for despicable reasons whereas those who foresee or are reckless as to harm merely fail to act for right reasons. Would that difference really underwrite a corresponding "difference in moral character," and indeed, a difference sufficiently great that it is properly codified in the criminal law? I suspect that the thought that it would rests on the view that the agent who acts for a despicable reason reveals himself to have a morally worse character than the agent who merely fails to accurately weigh costs and benefits, but who may well be, as Duff says, acting for reasons that are "perfectly legitimate." But that is too sweeping a conclusion to draw.

Compare two features of the law of homicide. In jurisdictions that follow the Model Penal Code, "extreme indifference to the value of human life" is sufficient to convict for murder. ${ }^{20}$ In contrast, what would otherwise be murder is downgraded to manslaughter if "committed under the influence of extreme mental or emotional disturbance for which there is reasonable explanation or excuse." 21 That suggests that someone who is (literally) reckless-without concern or care for the interests of others-can be adjudged to have committed a greater offense in causing death than someone who, though he very well intends to cause the harm he causes, acts out of an extreme and intelligible provocation. Suppose A gets a thrill out of driving at exceptionally high speeds down quiet neighborhood streets. One day, while indulging this pastime, A sees B in the crosswalk but, casually indifferent, speeds on and runs B over. Under the Model Penal Code, A is likely guilty of extreme indifference murder. Contrast $\mathrm{C}$, who purposefully, and wrongfully, runs over D, but does so out of extreme provocation; under the Model Penal Code, this clearly intended harm is treated as manslaughter rather than murder. What this suggests is that, to the extent that we see the provocation as mitigating the wrongness of what $\mathrm{C}$ does, we tend to see his actions as morally more tolerable. However, tolerable is a long way from permissible: that we see $\mathrm{C}$ as partially exculpated by D's provocation does not mean that we view C's actions as permissible. Far from merely ignoring decisive reasons not to $\mathrm{X}, \mathrm{C}$ affirmatively takes a reason against doing $\mathrm{X}$ as a reason to $\mathrm{X}$-in marked contrast to A, who after all does not take running $\mathrm{B}$ over as his reason for action, merely failing to care about B's interests. Consequently, if we are inclined to think that A's homicidal indifference ought to be treated more severely than C's reasonably provoked conduct, we cannot explain that result by assigning moral salience to the formal distinction between acting on a despicable reason versus acting without fully appreciating good reasons for not acting. It would be too simplistic to say that the moral character a person reveals is defined "intrinsically" or "essentially" by whether he intends harm, or foresees or is reckless as to it. The intent of the former may have a morally intelligible basis, while the recklessness of the latter may reveal genuine depravity.

\footnotetext{
${ }^{19}$ In some cases of foreseeable risk imposition, benefits and burdens are weighed against each other. Driving on the interstate will result in a certain foreseeable number of deaths and injuries each year, but that is outweighed by the benefit to everyone of having an efficient means of transportation. The point is that the weighing presupposes a prior validation of the reasons for action as legitimate in the first place.

${ }^{20}$ MPC $\$ 210.2(1)(b)$.

21 MPC $\$ 210.3(1)(b)$.
} 


\section{The Arithmetical Model}

It is worth re-emphasizing the issue in contention. That issue is not whether there is anything general to be said about the moral status of intended versus non-intended harming. The question is rather: is there something specific about intended harms that can underwrite the criminal law's insistence on a criminal purpose for attempts, even when the underlying offense is satisfied with something less? The question is one about the proper definition of attempts, that is, a question of criminalization: what should the scope of attempts be ? $^{22}$

I have thus far challenged Duff's proposals as to what might constitute the alleged uniqueness of intended harms; I now move to challenging the conclusion he suggests follows from it. My argument in this section is that the allegedly unique status of intended harms only supports the traditional mens rea rule of attempts if increased culpability is thought to offset absent or reduced harm, and that that conception of the relation between harm and culpability is seriously flawed.

Duff's emphasis on the moral "structure" or "character" of intended versus nonintended harms should perhaps strike us as mysterious. Duff argues that an attack is "more intimately related to the paradigm of crime than are acts of endangerment," and so we have reason "to treat failed attacks more seriously than we treat endangerments which actually cause no material harm." 23 As such, one who endangers is at most "potentially" harmful, unlike one who attacks, whose entire action is structured around the prospect of causing harm. ${ }^{24}$ One who endangers, Duff points out, may successfully complete his action without actually causing harm, whereas one who attacks succeeds only if she harms. But why does the moral character of the action matter? After all, even if recklessly or knowingly caused harms are not as "intimately related to the paradigm of crime," everyone agrees they are sufficiently intimate for such agents to be punished when they succeed in causing harm. Given that A's recklessness or foresight as to whether she imposes a harm on B is sufficient to convict when A does cause the harm, the observation that she would be even more culpable if she had intended the harm seems neither here nor there. So the question becomes, why does the absence of harm require a heightened degree of culpability?

The answer, I suspect, is this: there is a spectrum of acceptable criminalization ranging from a paradigmatic case (intended actual harm) to some threshold limit, the variables that jointly determine where on that spectrum a type of conduct falls are the culpability with which an agent acts and the harm he causes, and the function relating harm and culpability to where a type of conduct falls is arithmetic. Therefore, A, who fails to harm but does at least intend it, crosses the threshold, whereas B, who both fails to harm and does not intend it, falls below it. After all, that A attacked her victim at least makes her more blameworthy than $\mathrm{B}$, who did not. ${ }^{25}$ On this model, it then becomes relevant-indeed, it becomes crucial—whether there is a general distinction in moral kind between intended and nonintended harms. For if so, then there will be a significant difference between dangerous

\footnotetext{
${ }^{22}$ Duff (1996a, p. 368): in cases where the relevant harm does not materialize, "we have stronger reasons to criminalize failed attacks on legally protected interests than ....actions that recklessly endanger, but do not actually harm, such interests" (Emphasis added).

23 Duff (1996b, p. 41; 1995, p. 321).

24 Duff (1996a, p. 365).

25 Duff (1996a, p. 368). The victim who is recklessly endangered suffers a "categorically different...and less serious" harm and wrong than the victim of a failed attack, and consequently has a "weaker complaint" than the latter.
} 
conduct that is a (purposive) attempt, and dangerous conduct that is merely (non-purposive) endangerment. Even if a non-purposive level of culpability would have been sufficient had the agent actually caused the harm, the absence of harm means that the combined score falls below a criminalization threshold absent some increase in culpability. ${ }^{26}$ In other words, harm and culpability are mutually offsetting factors in constituting criminal responsibility, factors whose sum bring an agent above the threshold limit of acceptable criminalization or allow her to fall below it. I call this the "arithmetical" model of responsibility. ${ }^{27}$

Let me be clear: I do not say that anyone explicitly endorses this model of criminal responsibility. I am not asking what would be a plausible view of criminal responsibility. I am rather taking as fixed the arguments put forward for the mens rea rule of attempts, and asking what must be true if those arguments are to show what they are purported to show. For consider: if actual harm and culpability did not sum in this fashion, how would the fact-if such it is — that an attack has a different, and more serious, moral character than a non-attack show that only attacks can be attempts, given that non-attacks are perfectly sufficient for successful offenses? Why would it not show only that non-purposive attempts ought to be punished less severely than purposive ones? The admittedly intuitive thought that the reckless endangerer is two steps removed from the paradigm whereas the failed attacker is only one step removed only supports a rule about the definition of attempts if we suppose that these are two steps along one dimension, and that two steps takes one across a morally and legally significant threshold whereas one step does not. ${ }^{28}$ So my claim is that the arguments put forward in defense of the mens rea rule of attempts unavoidably imply this model, not that this model is independently plausible. For it is not a plausible model; in fact, it faces three objections which I believe are decisive.

First, we have no way of operationalizing the intuitive offsets suggested. What possible unit of weight can we use in assigning responsibility for an attitude of this sort or that sort versus differing kinds of harm, and differing degrees of harm? And even if we did find some measure, how would we know where to set the threshold cutoff? It is hard to see how we could specify, with any reasonable precision, and in a non-question begging manner, exactly how great an increase in culpability would be required to accommodate the missing harm in a prosecution for attempted murder versus attempted arson, robbery and so forth.

Second, the arithmetical model is inconsistent with the offense of reckless endangerment, an offense that not even the most committed defender of the traditional mens rea rule of attempts wants to discard. It is inconsistent with punishing reckless endangerment because, as noted above, the model sets-necessarily - a threshold for liability, for the definition of attempts. But if conduct that is reckless vis-à-vis some prohibited is less

\footnotetext{
${ }^{26}$ I think something along these lines provides the best interpretation of Lord Goddard's reasoning in Whybrow, since otherwise the claim that intent is the "essence" of attempt is both unsupported and quite mysterious. See Whybrow, 35 Crim. App. 141, 147 (1951) (per Lord Goddard, C. J.).

27 It has been suggested that I am uncharitable in construing the relation arithmetically rather than as, say, harm multiplied by culpability. But it is easy to see why the model must be arithmetic and not multiplicative: treating harm as a multiplier would prohibit punishing attempts (i.e., harmless wrongdoing) altogether.

${ }^{28}$ Note that the arithmetical model should not be understood as representing a general cut-off for any sort of criminal punishment whatsoever, but rather as a cut-off for liability for each category of recognized offense. That is, the threshold is set independently for each offense, rather than for criminalization just as such. Otherwise, the fact that shoplifting is a crime would then be taken to license virtually any form of inchoate liability for invasion of graver interests, which would undermine rather than support the traditional mens rea rule of attempts.
} 
culpable than conduct that is intentional vis-à-vis that result, and if the threshold is criminal purpose, then no liability should attach to mere recklessness. This result would be avoided if we interpreted the harm plus culpability score as a guide to how severely any given offender should be punished, but that would come at the cost of undermining the rule we set out to justify, since our model would then suggest that non-purposive attempts are punishable, just less severely than purposive ones. That might be a good idea, but it's clearly inconsistent with the traditional mens rea rule of attempts.

Third, and most importantly, if harm and culpability are mutually offsetting factors, we should expect that just as increased culpability offsets decreased harm, increased harm should offset decreased culpability. But this is clearly not the case. Suppose A is seized by a tornado and is hurled in B's direction, and B dies as a result of A falling on him. Is there any reason whatsoever to suppose that A ought to be held criminally responsible? What if A's fall kills two people? Or ten? At what point is the amount of harm so great that criminal responsibility is triggered? The answer, it is clear, is that there is no upper limit. Of course I do not mean that it would be unjustified to take action to prevent A from falling on B, even perhaps at the cost of A's life. I only mean that it would be unjustified to suppose that A was somehow (criminally) responsible for imposing the risk. If this is true, then what that suggests is that even an infinite weight of one value cannot offset less of another; and if that description is sound, then I think it is safe to say that the two values are not arithmetically related at all.

One might try to resist the argument of this section by pointing out that a far more plausible view of criminal responsibility is one in which some level of culpability is in all cases necessary, but which could, once established, be aggravated by the existence of actual harm. This model avoids the more serious problems plaguing the arithmetical model. But the crucial question is whether it supports the traditional mens rea rule of attempts. And, unfortunately, it is clear that it does not. After all, the degree of culpability necessary to convict of an offense is given by the mens rea provisions in that offense's definition. So if an offense may be committed with less than a criminal purpose, and in a concrete instance, an agent acts with precisely that (non-purposive) degree of culpability, then this model suggests that he is properly convictable of an attempt. Of course, as an attempt, it would be considered less aggravated than had he actually caused harm; but he would convictable of attempt nonetheless. Once again, while that might be a good result, it is inconsistent with the traditional mens rea rule of attempts, by which only purposive conduct counts as an attempt in law, irrespective of the mens rea provisions of the underlying offense. ${ }^{29}$

\section{The Continuity Thesis}

The gist of my argument thus far has been that the traditional restriction of attempt liability to crimes of purpose is not mandated by the greater culpability of attacks, any difference in reasons for action as between intended and non-intended harms, or an offsetting conception of criminal responsibility. I now suggest that we take a step back and take a broader view of attempt and endangerment, one that views attempt and endangerment as broadly continuous rather than as morally distinct genera of offense. On this view, the boundaries between attempt and endangerment in the law are essentially arbitrary, and do not mark anything of great independent moral significance. Both attempt and endangerment exist to

${ }^{29}$ My thanks to a reader at Criminal Law and Philosophy for pushing me to consider this objection. 
regulate unreasonably dangerous conduct, and that this function happens to be divided over two legal categories may be of historical or political, but not philosophical, interest. What I am calling the "continuity thesis" is offered in a functionalist spirit, by which I mean that the continuity between attempt and endangerment is a continuity in an underlying purpose the criminal law seeks to achieve, despite the relatively superficial difference in doctrinal form. That attempt and endangerment fulfill the same functional role is sufficient to view them as continuous, regardless of how they are individuated in law.

Because it is functionalist rather than formalist in orientation, there are multiple ways the continuity thesis can be realized. Two come readily to mind: the direct and indirect methods. The continuity between attempt and endangerment can be made explicit at the level of doctrinal form by rejecting the mens rea rule of attempts, and instead allowing an attempt conviction to stand whenever the agent acts with a mens rea sufficient for the underlying offense. ${ }^{30}$ That would be a direct instantiation of the continuity thesis. An indirect instantiation is much less intrusive at the level of statutory reform, so is probably to that degree more likely. This method retains attempts as currently defined-i.e., as reaching only those acting with a criminal purpose-but redefines endangerment by creating distinct categories of endangerment. Some would be graded, and punished, more severely than others, and at the high end would either attain or approximate the severity of traditional attempts. The more serious categories of endangerment would be construed to reach conduct that (a) had it actually caused harm, would have been a serious offense, and (b) was committed either recklessly or knowingly, but not with a criminal purpose. Thus, lousy driving would remain a relatively minor offense (a basic misdemeanor), whereas someone who recklessly or indifferently does what would have amounted to, say, rape or manslaughter, would be liable under the enhanced forms of endangerment. ${ }^{31}$ A jurisdiction that took either of these approaches would give practical effect to the continuity thesis. The main difference would be that a jurisdiction taking the indirect route would appear to retain a distinct role for attempts, while not giving that appearance any real effect, as all non-purposive "attempts" would be punishable under the enhanced endangerment statute, and punished to roughly the same degree as they would have been had they been brought under a broad attempt statute in a direct jurisdiction. ${ }^{32}$

Obviously, there might well be practical reasons for choosing the indirect or direct methods. Perhaps for an institutional structure that relies heavily on prosecutorial charging discretion, and in which prosecutors are responsive to popular political pressures, a direct route would risk great prosecutorial over-reaching. An indirect route might (or might not) mitigate this difficulty, at least if the enhanced categories of endangerment were defined with some specificity. If that were so, then someone convinced that, for instance, the

\footnotetext{
30 A jurisdiction adopting this approach should also abolish reckless endangerment, as the newly defined attempt statute would do all the work endangerment currently does (and more), and abolishing endangerment would eliminate the risk of absurdities such as attempted endangerment offenses.

31 Cahill (2007) notes that many jurisdictions in the United States have general purpose reckless endangerment statutes, or specific ad hoc endangerment offenses, or both. Hawai'i, discussed below, is a case in point. These jurisdictions, as I see it, are taking halting steps toward indirectly incorporating the continuity thesis. As Cahill astutely points out, this approach is not without dangers of its own (see Cahill 2007, pp. 930ff.).

32 Enker ends his defense of the purpose requirement by suggesting that "the substantive crime of reckless risk creation might well be broken down into the different types of recklessness, and even to intentional risk creation, with appropriate penalty levels for each category of offense" (Enker 1977, p. 866). I am inclined to believe this is to merely pay lip service to the idea that attempts must be purposive.
} 
United States suffers from a problem of "overcriminalization" due to overly broad criminal statutes would have reason to prefer the indirect over the direct method. ${ }^{33}$

The basic point, however, is that even if attacks do have a unique moral character or intentional structure, legal regulation of unreasonably dangerous conduct should take that into account at the level of punishment, not at the level of criminalization. One might still insist that there is a fair labeling argument for distinguishing attempts - as the worst of the lot-from mere endangerments. I have no quarrel with that, so long as we are clear that attempt and endangerment are two species of one (functional) genus, and to be treated accordingly.

The most important advantage of implementing the continuity thesis in either form is that it fills a gap that is created by the restriction of attempts to criminal purpose. After all, conduct that is ex ante substantially likely to invade another person's protected interests without excuse or justification is both blameworthy and dangerous. In the cases in which whether a person's conduct actually causes harm is purely a matter of luck, it seems anomalous to prohibit if, as luck would have it, she causes harm but to permit if she does not. But this is precisely the effect of the traditional mens rea rule of attempts. For suppose that A fires at B without actually intending (or even desiring) B's death-simply because, say, she thinks it would be a humorous way of killing a fly perched on B's nose. The traditional mens rea rule of attempts, strictly construed, implies that whether $\mathrm{A}$ is or is not punishable depends on whether she happens to actually kill B. But that makes A's liability a matter of luck, which seems to be the wrong result, as A seems blameworthy and highly dangerous regardless of what happens. At the moment A announces her plan of action, we know that A acts wrongly, and indeed seriously so; and our confidence in this judgment is not based on our belief that B will be killed. Rather, our confidence in our assessment of the wrongfulness of A's actions is that it risks B's life for morally stupid reasons; and insofar as the legal basis of blame should track the moral basis, it seems proper to view A as punishable regardless of the outcome.

To be fair, it is not strictly true that $\mathrm{A}$ is not punishable at all if she does not kill B; for she is often still liable for reckless endangerment. But under the Model Penal Code, reckless endangerment is a generic, one category offense that carries a maximum penalty of 1-year imprisonment. ${ }^{34}$ This seems to be disproportionately lenient once we consider that had A actually killed B, she would be on the hook for murder, and would face the most serious penalties available. In contrast, under either of the regimes described above, A would be liable for at least attempted manslaughter and perhaps attempted extreme indifference murder (direct), or a highly aggravated form of endangerment, with a correspondingly severe penalty (indirect).

A second advantage of the continuity thesis is that it eliminates puzzling asymmetries created by a regime that recognizes only generic, misdemeanor endangerment and traditionally defined attempts. Thus, if A intends to burn B's barn, she is liable for a seconddegree felony, whereas if she recklessly shoots at B at close range, she has committed at most a misdemeanor, even though the latter act is both more dangerous and more reprehensible. ${ }^{35}$ Under either a direct or indirect approach, A's conduct in the latter case would

\footnotetext{
33 See Husak (2007) generally, and Cahill (2007 pp. 938ff.), on the merits of "thick" and "thin" criminal codes.

34 MPC §211.2, §6.08.

35 MPC $\$ 5.05(1), \S 220.1(1)(a)$. State legislatures occasionally draft specific ad hoc offenses to deal with these kinds of troublesome cases, often specifically out of a sense that general endangerment would not be sufficient.
} 
not be given the windfall that the traditional scheme provides, and would be brought in line with cases of similar dangerousness and culpability.

Third, since it does not rely on a distinction between intended and foreseen harms, the continuity thesis sidesteps the enormously difficult question of how that distinction is to be drawn. ${ }^{36}$ The criteria for deciding whether a person intended a consequence or merely foresaw it are notoriously unreliable and malleable. (Sanford Kadish goes so far as to say "sophistical." ${ }^{37}$ ) It is very difficult, in the abstract, but especially in law, to show precisely what a person subjectively did or did not intend, as it is often almost impossible to rule out with the requisite degree of certainty non-intentional explanations for a person's conduct. Of course, insofar as there are substantive offenses that require purpose, and insofar as purpose is viewed as a specially aggravating sentencing factor, the continuity thesis does not entirely escape this problem; but since it does not impose an additional purpose requirement on all attempts, it at least does not exacerbate it in the way the mens rea rule of attempts does.

These advantages are not purely hypothetical, existing in the realm of theory but immaterial to practice. In difficult cases arising in traditional jurisdictions, prosecutors and courts can be seen on the record trying their best to dodge the paradoxical results occasionally demanded by the mens rea rule of attempts. If I am right that there is a gap in need of filling, then their motivation for doing this is evident: they feel that the alternative-a misdemeanor with a relatively light penalty-is too lenient in view of the grave and unwarranted risks imposed by a given defendant's conduct, so they strive to find some more or less ad hoc basis for an attempt conviction. One of the means that is employed to achieve an attempt conviction under these circumstances is the doctrine that one intends the natural and foreseeable consequences of one's acts. ${ }^{38}$ But since it allows the prosecutor to prove facts that are completely consistent with non-purposive explanations of an agent's conduct, this move seems to duck the purpose requirement rather than instantiate it. The facts thus proved are often entirely consistent with, for instance, the agent expecting or not caring about a given outcome, or indeed, simply being grossly negligent. The prop of "natural and foreseen consequences" undermines the very point of requiring criminal intent, if a prosecutor and court can evade that restriction whenever it is perceived to be inconvenient or arbitrary on the facts of a particular case. It would probably be better to acknowledge openly, as the continuity thesis does, that an actual criminal purpose is not necessary to impose serious penalties for very dangerous and culpable conduct.

I conclude by considering some cases.

A good illustration of the gap-filling advantage of a continuous regime is seen by contrasting Jones $v$. State with State $v$. Rumbawa. ${ }^{39}$ In Jones, the defendant approached a house and fired several shots through its windows and doors. As a result, A was killed and B wounded. At trial, Jones was convicted of murdering A but acquitted of attempting to murder B. On appeal, Jones challenged his murder conviction on the ground that that it was inconsistent to convict for murder while acquitting for attempted murder, as "if the jury did

\footnotetext{
36 This issue is familiar from the literature on double effect. For a sampling of this extensive literature, see Anscombe (2001), Bennett (1981), Fischer et al. (1993), Foot (1985, 2001), Hart (2008), McIntyre (2001), Quinn (1989), Scanlon (2008) and Simester (1996).

37 Kadish (1987, p. 115).

38 Compare State v. Perez, 832 A.2d 303 (N.J. 2003) and State v. Hinkhouse, 912 P.2d 921 (Or. App., 1996), discussed below, to Keys v. State, 766 P.2d 270 (Nev. 1988). See also Cahill (2007, p. 895).

39 Jones v. State, 689 N.E.2d 722 (Ind., 1997), State v. Rumbawa, 17 P.3d 862 (Hawai'i App. 2001). See also People v. Trinkle, 369 N.E.2d 888 (1977).
} 
not find that the defendant intentionally attempted to kill [B], then it could not reasonably find that he intentionally killed $[\mathrm{A}] .{ }^{, 40}$ Jones pointed out that the shots were fired in such rapid succession that it was not plausible that the bullet that happened to strike A was "intended" to kill while the one that struck (but did not kill) B was not: he should have been convicted or acquitted on both counts. Applying the traditional mens rea rule of attempts, the appellate court rejected the challenge: attempted murder required the jury to find that Jones acted "with intent to kill the victim," whereas conviction for murder could be satisfied if the jury found that he "was aware of a high probability that the victim's death could result from his actions." 41 Therefore, Jones was properly convicted of murdering A and acquitted of attempting to murder B. Had Jones been brought in a jurisdiction that made attempts mens rea equivalent to the underlying offense, Jones would have been convictable of attempted murder of B or, if the facts warranted it, attempted reckless homicide, a crime that is more or less impossible under the traditional regime. ${ }^{42}$ If Jones had been brought in an indirect jurisdiction he would have been convictable of felony endangerment, and would have faced penalties not quite as severe as attempted murder, but more severe than mere misdemeanor-arguably a more appropriate outcome than that reached in Jones.

In State v. Rumbawa, the defendant was charged with attempted second-degree murder for shooting at a police officer. At trial, he was convicted instead of reckless endangering in the first degree, which Hawai'i classifies as a felony. The Hawai'i Intermediate Court of Appeals rejected the defendant's challenge that reckless endangering was not a lesserincluded offense of attempted second-degree murder. The court pointed out that the legislature had expressly decided to include intentional firing of a firearm "in a manner which places another person in danger of death or serious bodily injury" in a revised endangerment statute, and indeed, precisely out of a sense that misdemeanor endangerment was inappropriately lenient for that kind of conduct. ${ }^{43}$ The court concluded that it was proper to treat (felony) endangerment as a lesser-included offense of attempted murder-thus establishing a clear legal continuity between attempt and endangerment.

In State v. Hinkhouse, the defendant was informed that he had tested positive for HIV, that HIV was inevitably fatal and transmissible through sexual contact, and that he would be held responsible if he were to transmit it to others. ${ }^{44}$ Ignoring the warning, Hinkhouse proceeded to have sexual relations with several different women. He consistently concealed or lied about his condition and refused to wear a condom during sex; as a result, at least one of his sexual partners acquired HIV. Hinkhouse appealed his conviction for attempted murder, insisting that while he was not unaware of the risk he was imposing, he did not intend to transmit HIV but only to obtain "sexual gratification." Hinkhouse's appeal was rejected, on grounds that his knowledge concerning HIV and his conduct showed that he intended to kill. But the argument for this was unconvincing, as Hinkhouse's conduct was (with one exception) perfectly consonant with indifference rather than an actual intent to kill. ${ }^{45}$

\footnotetext{
40 Ibid. at 724 .

41 Ibid. at 724.

42 See Cahill (2007).

43 Hawai'i Revised Statutes §707-713 (1993).

44 State v. Hinkhouse, 912 P.2d 921 (Or. App. 1996).

45 The one exception is that Hinkhouse reportedly boasted that he would spread HIV if he were infected with it. Oddly, the court but did not seem to place great weight on this statement, although it is the only piece of evidence on the record that would serve to support the attempt conviction. If the court had been
} 
Hinkhouse perfectly illustrates the contortions that prosecutors and courts will go through to sidestep the traditional mens rea rule of attempts. (Oregon, where Hinkhouse was litigated, follows the traditional rule. ${ }^{46}$ ) It is at best unclear that Hinkhouse was properly convicted under the mens rea rule of attempts - had he kept his mouth shut, it would have certainly been improper. The prosecutor was faced with the unenviable choice between charging too leniently (misdemeanor endangerment), or over-reaching (purposive attempt), and might well have opted for the latter, hoping to convince the court to find intent to kill through a doctrine of implied malice. This would be a reasonable wager if judges and juries, like prosecutors, are indeed likely to find the kind of conduct in question seriously repellent - though it is a wager that, I have suggested, accepts the letter of the purpose requirement while violating its spirit. In contrast, under either the direct or indirect implementation of the continuity thesis, the central issue would have been whether Hinkhouse's acted despite a "practical certainty" (in Model Penal Code terms) that doing so would be tantamount to killing his sexual partners. If not, a prosecutor would have seen an advantage to charging downwards-e.g., for something along the lines of either attempted manslaughter (direct) or highly aggravated endangerment (indirect), rather than attempted murder; and it would be difficult indeed for Hinkhouse to show that he was not at least reckless. (Attempted reckless homicide or extremely aggravated endangerment may also be a more accurate characterization of Hinkhouse's conduct.)

Does the continuity thesis extend criminal liability too broadly? I conclude by considering some hypothetical cases where it might seem that the continuity thesis would yield overly harsh results.

First, suppose, that A forces himself on B, and hopes that her show of resistance is merely a show, though he has no reason to believe that to be true. Would it be overly harsh to convict A of attempted rape (or even some form of endangerment) if it turns out (unknown to $\mathrm{A}$ ) that she does consent? ${ }^{47}$

I concede that the continuity thesis would suggest A is convictable. (Whether a prosecutor would ever actually intervene in a case like this is of course another question.) But is this the wrong result? Given that A has no reason to think that B's resistance is in fact some kind of elaborate show, A's belief that B may nevertheless consent is patently unreasonable. Moreover, that A nevertheless "hopes" B consents is not mitigating, as this putative hope is at best idle, and quite possibly self-serving. After all, it is unconnected with his

\section{Footnote 45 continued}

strict about the rule it purported to be applying, the only question would have been whether this reported statement (and it alone) would have been enough to allow a jury to find criminal purpose beyond a reasonable doubt. Contrast Hinkhouse with Smallwood v. State, 680 A.2d 512 (Md. 1996), in which the Maryland Court of Appeals overturned the convictions of an HIV positive rapist for attempted murder because the state had failed to show specific intent, for instance through "explicit statements demonstrating an intent to infect" or "specific actions demonstrating such an intent and tending to exclude other possible intents" (Ibid. at 516). Similarly, in Keys v. State, 766 P.2d 270 (Nev. 1988), Keys was fleeing the scene of a murder and demanded that a passerby drive him away; when the passerby refused, Keys pointed a gun at him and pulled the trigger twice, but the gun failed to fire. At trial, he was convicted of attempted murder based on "implied malice," viz. that his intent to kill could be inferred from his conduct. The appellate court overturned his conviction, since malice must be express for attempt-that is, the prosecutor must show that the defendant actually intended the criminal result, not merely point to conduct from which intent might (but need not) be inferred.

46 Ore. Rev. Stat. $\$ \$ 161.405$ and 163.195 .

47 For further discussion, see Duff (1996a, p. 374), Finkelstein (1999, p. 74) and Williams (1983) generally. Discussion of this kind of case is sometimes structured with reference to the distinction between the consequences and circumstances of an offense. As I am unsure of the weight this distinction will support, my discussion in the text does not mention it. 
practical reasoning, and so is inconsistent with the point of caring about consent, namely respecting the sexual autonomy of others by taking consent as decisive. Since A's supposed concern with B's consent is idle in this manner, the fact that, as it turns out, B does consent should consequently also be discounted: that had nothing to do with A's decision about whether or not to proceed. However, in light of the unique nature of the harm at issue in rape-an attack on another's sexual autonomy - the fact that B did consent, albeit secretly, would suggest that even though A is convictable, the punishment, if any, should be relatively minor.

Second, would identifying the culpability requirements of attempt with those for the underlying offense immediately transform every case of, say, drunk driving into attempted manslaughter? Drunk driving is surely blameworthy, but that seems excessive.

Would it also seem excessive in the case of someone who fires a gun randomly into a crowd, but fails to actually hit anyone ${ }^{48}$ If not, what is the relevant difference in the case of the drunk driver? The answer, I think, has to do with our sense of the scope, and degree, of risk that the two agents impose. Considered in the abstract, it is unclear whether the greatest risk a drunk driver poses is to others, to himself or to property, and how severe a risk it is in each case. Given this kind of indeterminacy, it would be gratuitous to immediately treat every case of drunk driving at the top of the scale, as attempted manslaughter. If we fill in the facts somewhat in particular cases (A drives drunk on the interstate at rush hour, or drives a few hundred yards down an unpopulated, country road at 3 a.m.), the sense of the appropriate inchoate crime to charge, if any, becomes clearer. In extreme cases, an attempted manslaughter charge might very well be the correct charge, but there seems to be little reason to think that every instance of drunk driving should automatically be described in that fashion. So acceptance of the continuity thesis does not imply that every case of vaguely dangerous conduct should instantly be converted into a serious criminal offense. ${ }^{49}$

In a more general vein, accepting the continuity thesis does not commit a theorist to thinking that every defined offense should have an inchoate counterpart. The argument here assumes that criminalizing a certain kind of dangerous conduct is appropriate. If it is not in a given case, then the argument simply does not apply to it. Thus, the complaint that the continuity thesis ignores the relevance of resulting harm, being obsessed with bringing the least bit of harmless but culpable behavior within the scope of the criminal law, misses the mark. There are certainly cases of culpable conduct which ought to be punished if they actually succeed in causing harm, but are otherwise too trivial to bother with. For instance, if A steals B's bicycle, she inconveniences B, and damages his ability to expect his property to be where he leaves it, available for his sole use. That might require the law to take notice of A's conduct. But if A fails in her attempt, then it might well be counterproductive to engage the gears of the criminal law for such de minimis conduct. But nothing I have said should suggest the contrary. Criminalizing A's failed attempt might be consistent with the continuity thesis, but is certainly not required by it. The continuity thesis is simply silent on whether any given class of culpable but non-harmful conduct is properly punished, even though it might in principle be punishable. ${ }^{50}$

\footnotetext{
48 See State v. Vigil, 842 P.2d 843 (Utah 1992).

49 For a sensitive, and enlightening, discussion of the different categories of endangerment offenses (see Duff 2005, pp. 53-64).

50 I thus completely agree with Duff's skepticism that the law of attempts should extend to cover crimes (such as those regulating illegal drugs) that are themselves essentially inchoate, or where the risks are too remote, or the conduct too unremarkable (see Duff 1996a, p. 377).
} 


\section{Concluding Remarks}

I have argued for the following propositions. First, describing attempts as "attacks" either fails to explain why they are uniquely wrongful, or does so at the cost of being seriously under-inclusive. Second, it is at best unclear that the "intentional structure" of a person who intends rather than foresees or is reckless as to harm carries sufficient moral weight that the law of attempts is rightly structured around this distinction. Third, be that as it may, the attempt to ground the mens rea rule of attempts on the unique moral character of intended harms presupposes an unworkable model of criminal responsibility. Fourth, we should adopt the continuity thesis, according to which endangerment and attempt are not functionally distinct kinds of crime, but merely two means of legally regulating unreasonably dangerous conduct. This can be done by defining attempts broadly as mens rea equivalent to the object offense, or by leaving attempt narrowly defined, while broadening, and articulating, the various forms of endangerment to fill the gap. Finally, adopting the continuity thesis in either form would improve the predictability of the criminal law, rather than leaving it to courts and prosecutors to invent questionable ways of evading the spirit of the law while respecting its letter.

The traditional mens rea rule of attempts is not costless. In concert with the underdeveloped law of endangerment, it entails that agents who are both culpable and dangerous are either not punished, or punished disproportionately leniently if, as luck would have it, they do not cause harm, although they would be paradigm cases for serious punishment if they did. These are costs both in terms of punishing in accord with desert, when measured by the agent's choices, and in terms of raising the costs of criminal conduct by punishing not just "success," but failure as well. Whether these costs are sufficient to finally make out a case for legal reform depends on complicated questions of policy and politics that I have not addressed. But insofar as we view matters of principle as constraints on the development of policy, surely it is of some value to learn that the room for innovation in this area is not nearly as constricted as has sometimes been suggested.

Acknowledgements This paper was greatly improved thanks to detailed and incisive comments by anonymous referees at Criminal Law and Philosophy. Adriaan Lanni, Daryl Levinson, Ken Simons and Carol Steiker, as well as participants in the Harvard Law School Criminal Justice Workshop, read and provided detailed comments on earlier drafts. Work on this paper was completed with the support of the Reginald F. Lewis Fellowship at Harvard Law School, for which I am extremely grateful.

\section{References}

Alexander, L., \& Kessler, K. (1997). Mens rea and inchoate crimes. Journal of Criminal Law and Criminology, 87(4), 1138-1193.

Anscombe, G. E. M. (2001). Action, intention and 'double effect'. In P. A. Woodward (Ed.), The doctrine of double effect (pp. 50-66). Notre Dame: University of Notre Dame Press.

Ashworth, A. (1988). Attempts and resulting harm. Rutgers Law Journal, 19, 725-772.

Bennett, J. (1981). Morality and consequences. The Tanner Lectures on Human Values, 2, 47-116.

Bittner, T. (2008). Punishment for attempts: A legal perspective on the problem of moral luck. Canadian Journal of Philosophy, 38(1), 51-84.

Cahill, M. (2007). Attempt, reckless homicide, and the design of criminal law. University of Colorado Law Review, 78, 879-956.

Dressler, J. (2007). Cases and materials on criminal law. St. Paul: West Publishing.

Duff, A. (1989). Intentions legal and philosophical. Oxford Journal of Legal Studies, 9(1), 76-94.

Duff, A. (1990). Intention, agency and criminal liability. Oxford: Basil Blackwell.

Duff, A. (1995). Recklessness in attempts (again). Oxford Journal of Legal Studies, 15(2), 309-325. 
Duff, A. (1996a). Criminal attempts. New York: Clarendon Press.

Duff, A. (1996b). Subjectivism, objectivism, and criminal attempts. In A. P. Simester \& A. T. H. Smith (Eds.), Harm and culpability (pp. 19-44). Oxford: Oxford University Press.

Duff, A. (2005). Criminalizing endangerment. In R. A. Duff \& S. P. Green (Eds.), Defining crimes (pp. 43-64). New York: Oxford University Press.

Enker, A. (1977). Mens rea and criminal attempt. American Bar Foundation Research Journal, 2(4), 845-879.

Finkelstein, C. (1999). No harm no foul? Objectivism and the law of attempts. Law and Philosophy, 18(1), 69-84.

Fischer, J. M., Ravizza, M., \& Copp, D. (1993). Quinn on double effect: The problem of closeness. Ethics, 103(4), 707-725.

Foot, P. (1985). Morality, action and outcome. In T. Honderich (Ed.), Morality and objectivity (pp. 23-38). London: Routledge Kegan \& Paul.

Foot, P. (2001). The problem of abortion and the doctrine of double effect. In P. A. Woodward (Ed.), The doctrine of double effect (pp. 143-155). Notre Dame: University of Notre Dame Press.

Hart, H. L. A. (2008). Intention and punishment. In H. L. A. Hart (Ed.), Punishment and responsibility (2nd ed., pp. 113-136). Oxford: Oxford University Press.

Husak, D. (1997). Review: Attempts and the philosophical foundations of criminal liability. Criminal Law Forum, 8, 293-310.

Husak, D. (2007). Overcriminalization. Oxford: Oxford University Press.

Kadish, S. (1987). Blame and punishment. New York: Macmillan.

McIntyre, A. (2001). Doing away with double effect. Ethics, 111(2), 219-255.

Quinn, W. (1989). Actions, intentions and consequences: The doctrine of double effect. Philosophy \& Public Affairs, 18(4), 334-351.

Robinson, P. (1997). Structure and function in criminal law. Oxford: Oxford University Press.

Scanlon, T. (2008). Moral dimensions. Cambridge: Harvard University Press.

Simester, A. P. (1996). Why distinguish intention from foresight? In A. P. Simester \& A. T. H. Smith (Eds.), Harm and culpability (pp. 71-102). Oxford: Oxford University Press.

Smith, J. C. (1957). Two problems in criminal attempts. Harvard Law Review, 70(3), 422-448.

Smith, J. C. (1962a). Two problems in criminal attempts reexamined-I. The Criminal Law Review, $135-144$.

Smith, J. C. (1962b). Two problems in criminal attempts reexamined-II. The Criminal Law Review, 212-222.

Stuart, D. (1968). Mens rea, negligence and attempts. The Criminal Law Review, 647-662.

Wechsler, H., Jones, W. K., \& Korn, H. (1961a). The treatment of inchoate crimes in the model penal code of the American law institute: Attempt, solicitation and conspiracy. Columbia Law Review, 61(4), 571-628.

Wechsler, H., Jones, W. K., \& Korn, H. (1961b). The Treatment of inchoate crimes in the model penal code of the American law institute: Attempt, solicitation and conspiracy. Columbia Law Review, 61(6), 957-1030.

Williams, G. (1983). The problem of reckless attempts. The Criminal Law Review, 365-375. 